\title{
Glosario $\mathbf{C}+\mathbf{R}$, una estrategia de trabajo colaborativo
}

\section{Jose Madrid García ${ }^{\mathrm{a}}$, María del Pilar Bosch Roig y Lucia Bosch Roig}

${ }^{a}$ Dpto. de Conservación y Restauración de Bienes Culturales, Universitat Politècnica de València (jmadrid@crbc.upv.es), ${ }^{b}$ Dpto. de Conservación y Restauración de Bienes Culturales, Universitat Politècnica de València (mabosroi@upvnet.upv.es), ${ }^{\mathrm{c}}$ Dpto. de Conservación y Restauración de Bienes Culturales, Universitat Politècnica de València (lubosroi@crbc.upv.es).

\section{Abstract}

There are many objectives that can be achieved through the use of the not-so "new technologies" and one can be to improve communication between students and teachers. Communication that presents many difficulties when the teaching subject has a very high theoretical component.

That is why, a tool has been designed to enhance communication channels between students and the teacher. It has been developed in the subject 'Theory of Conservation and Restoration of Cultural Heritage', from the Degree of Conservation and Restoration of Cultural Heritage. Degree offered at the Polytechnic University of Valencia, Spain. A collaborative platform, where the student is the protagonist, has been created. Through this tool, there is also the aim to generate a highest student participation changing a possible negative perception of the subject on some students. The tool is called 'Glossary $C+R$ '. It is a website created in the academic year 2014/15 that has been improved since then thanks to the intervention of the subject's students, who have voluntarily participated. Platform that allows access at any time from all kinds of devices with internet access.

Keywords: Collaborative learning, cooperative learning, network learning, active methodologies, motivation

\section{Resumen}

Son muchos los objetivos que se pueden alcanzar con el uso de las ya no tan 'nuevas tecnologías': uno de sus enfoques puede ayudar a mejorar los canales de comunicación entre el alumno/a y el profesor. Comunicación que presenta muchas dificultades cuando la docencia en la asignatura tiene una componente teórica muy elevada.

Es por ello por lo que en la asignatura 'Teoría de la Conservación y Restauración de Bienes Culturales', que se imparte el Grado de Conservación y Restauración de Bienes Culturales en la Universitat Politècnica de València, se ha diseñado una herramienta que quiere potenciar esos canales de comunicación entre el alumno/a y el profesor. Creando una plataforma de colaboración, donde el estudiante es quien va a ser el protagonista. Y a través de este sistema pasar de una posible percepción negativa de la asignatura a un escenario donde se genere una mayor implicación. El sitio web 'Glosario $C+R$ ' se creó en el curso académico 2014/15 y se ha ido mejorando desde entonces gracias a la intervención de los alumnos/as de la asignatura, que de forma voluntaria han participado. Plataforma que permite el acceso, en cualquier momento desde todo tipo de dispositivos que tengan la posibilidad de conexión a internet. 
Palabras clave: aprendizaje colaborativo, aprendizaje cooperativo, aprendizaje en red, metodologías activas, motivación.

\section{Introducción}

La lección magistral, o método expositivo, poco a poco se está viendo desplazado como método principal de enseñanza/aprendizaje en todo el ámbito universitario. La docencia ha incorporado nuevos planteamientos y estrategias, que son soluciones como; recursos multimedia, gamificación de los contenidos, o foros de encuentro en plataformas digitales, entre otros.

Pero la lección magistral, que tiene como objetivo presentar un tema estructurado lógicamente y a través de la exposición por parte del profesor de los contenidos sobre la materia objeto de estudio (De Miguel, 2005), adquiere una ventaja frente a otras metodologías. Porque con ella tenemos la posibilidad de transmitir una gran cantidad de información a un número elevado de estudiantes. Siendo este el planteamiento que se ha venido empleando en la asignatura de la Teoría de la Conservación y Restauración de Bienes Culturales. Asignatura que se imparte en el segundo cuatrimestre de tercer curso en el Grado de Conservación y Restauración de Bienes Culturales. Grado ofertado por la Facultad de Bellas Artes de San Carlos en la Universitat Politècnica de València. Pero como afirma Gerritsen (1999), en este contexto de aprendizaje se corre el riesgo de que los estudiantes adquieran conocimientos y tras su evaluación los olviden, por no tener ningún significado para ellos. De la misma manera, la lección magistral se aleja del trabajo multidisciplinar que es el marco en el que se van a desarrollar los futuros profesionales.

Los nuevos modelos educativos, básicos para la adecuación al Espacio Europeo de Educación Superior (EEES), pueden ayudar a corregir esta situación gracias a la implementación de las nuevas tecnologías. Estrategias que pasan especialmente por el uso de comunidades virtuales y redes sociales (Garrigós et al., 2015). Igualmente, estas nuevas herramientas permiten el desarrollo de los procesos de gestión colaborativos, gracias a los nuevos sistemas de información y comunicación (Stewart, 2007).

La creación de un sitio web, como es Glosario $C+R$ (http://glosario.ldr.webs.upv.es/), posibilita el trabajar en el ámbito del denominado aprendizaje cooperativo (McCaffert, Jacobs y DaSilva Iddings 2006), también llamado aprendizaje colaborativo (Chung 1991, Romney 1997). Aprendizaje fundamentado en la interdependencia positiva y la capacidad individual de la práctica de sus miembros. Relación de dependencia recíproca que promueve en el alumno/a su responsabilidad y crean un compromiso con la tarea compartida (Johnson, Jonhson y Holubec, 1998; Slavin, 1990; Kagan, 1989). A través de la implicación del alumno/a en el proyecto de Glosario $C+R$, se ha querido disminuir la figura y protagonismo del docente para convertir al alumno/a en el verdadero protagonista, exigencia que rige ese cambio metodológico y de esta manera conseguir un aprendizaje más significativo (AguadedGomez, 2001). Aprendizaje que quiere ser permanente y que por ello debemos entender que hay múltiples formas de aprendizaje (Clemans, 2015), donde los recursos de Internet ocupan un lugar muy importante.

En este trabajo colaborativo el profesor busca motivar al alumno/a no solo para que participe con él, sino que pone a su disposición una plataforma en la que puedan colaborar entre ellos. Herramientas que permiten que, tanto el profesor como los alumnos/as, puedan trabajar en el momento que consideren, adaptándose a su mejor planificación temporal. Valiéndose en este proceso de los diversos niveles de colaboración y reciprocidad que se plantean en este tipo de aprendizaje (Dillenbourg, 1999; Laal y Laal, 2011; Smith y McGregor, 1992; Suárez y Gros, 2013). Proceso donde el alumno/a, como figura central, debe de aprender a aprender, siempre guiado por la figura del profesor que tiene la misión de retroalimentarle (Díaz, 2002; Vanhoof, 2005; García y Amante, 2006). Al mismo tiempo, como señalan 
Astin (1993) o Hake (1998), con esta estrategia pretendemos, incrementar la atención y participación del alumno/a en el aula, mejorar su motivación por la asignatura y el tiempo de dedicación a la misma fuera de las sesiones de aula.

\section{Objetivos}

La actividad de aprendizaje colaborativo, presentada en este artículo y a través del sitio web Glosario $C+R$, como se ha comentado persigue mantener interés y participación del alumno/a una vez terminada la sesión de aula y paralelamente trabajar otras capacidades de tipo transversal que son de gran importancia para su desarrollo. Teniendo la meta de fomentar la figura del estudiante autónomo, como sujeto activo de su propio aprendizaje. Alumnos/as que, como indica Pozo y Monereo (1999), formula sus metas, organiza el conocimiento, construye significados, utiliza estrategias adecuadas y elige los momentos que considera pertinentes para adquirir, desarrollar y generalizar lo aprendido.

Con ello se pretende, a través de los siguientes objetivos:

- Integrar un aprendizaje activo y colaborativo dentro de la asignatura mediante la confección de un repositorio común, al que todo el grupo tiene acceso en cualquier momento.

- Motivar a los alumnos/as en la asignatura, captando su atención y su implicación, con posibilidades que vayan más allá de los métodos ya probados como son los trabajos tutorizados.

- Establecer mecanismos de comunicación diferentes a los empleados en el entorno académico.

- Favorecer la asimilación de contenidos relativos.

\section{Desarrollo de la innovación}

Ya son muchas las evidencias en relación con un aumento en el aprendizaje a través del uso de aplicación web dentro del entorno de una asignatura (Thoms y Eryilmaz, 2015). Evidencias que ya han demostrado otras plataformas, todas ellas ofreciendo ventajas como; su inmediatez (Dunlap y Lowenthal, 2009; Tess, 2013), la relación entre los propios alumnos/as de un grupo (Grosseck y Holotescu, 2008), o entre profesores (Carpenter y Krutka, 2014), entre otras. De igual modo, la aplicación web fomenta y promueve la motivación de los estudiantes, ya que proporciona elementos de disfrute y la presencia social (Noguera, 2015), y mejorar el ambiente de trabajo (Miguel y Fernández, 2013) con el consiguiente aumento de la participación en el aula (Welch y Bonnan-White, 2012).

Y como vuelve a apuntar Grosseck y Holotescu (2008) permite la interrelación entre estudiantes de otras escuelas y países. Todos los estudios referenciados señalan, como aspectos positivos, el aumento del compromiso por parte del alumno/a en la asignatura y su sentido de pertenencia, incluso en aquellos que son especialmente introvertidos (Guzmán et al., 2012), o que se sienten inhibidos a hablar con el profesor (Carpenter, 2014).

Por todo ello, uno de los principales objetivos que se persiguen es promover un rol activo dentro del grupo de usuarios, donde el interactuar les permita desarrollar un repertorio compartido de recursos (Suarez, 2012). Además, el hacer accesible la información a todo el grupo en tiempo real, con la premisa de evitar la duplicidad de referencias, ha obligado a una investigación en mayor profundidad, que ha repercutido en el interés y la diversidad de los proyectos. 


\subsection{Marco tecnológico de desarrollo}

El sitio Glosario $C+R$ consta de una aplicación web, desarrollada mediante tecnología PHP y MySQL, con interfaz basada en HTML, CSS y JavaScript. Aplicación que se ha diseñado y creado por los propios responsables de la asignatura. El lenguaje PHP es un estándar para el desarrollo de sitios web dinámicos, soportado en la gran mayoría de estándares que utilizan los navegadores actuales. Por otro lado, MySQL, considerada como la base de datos de código abierto más popular del mundo, es un motor de base de datos relacional SQL, rápido y multiusuario, que se integra perfectamente con PHP permitiendo el acceso a la base de datos de forma eficaz.

El planteamiento principal para su diseño fue ante todo la claridad de los objetivos planteados, dirigidos a agilizar la experiencia del usuario en su navegabilidad, ofreciendo un acceso rápido a todas las funcionalidades propuestas en el sitio (fig.1). Para su diseño se pensó por un lado en el estudiante como usuario y por otro lado en el perfil del administrador. $\mathrm{Y}$ en el caso de éste intentando aligerar todas las tareas de consulta, mantenimiento y contacto con los usuarios. Dentro del sitio web, el administrador podrá supervisar y coordinar soluciones ante posibles errores y problemas relacionados con los términos que se van ingresando.

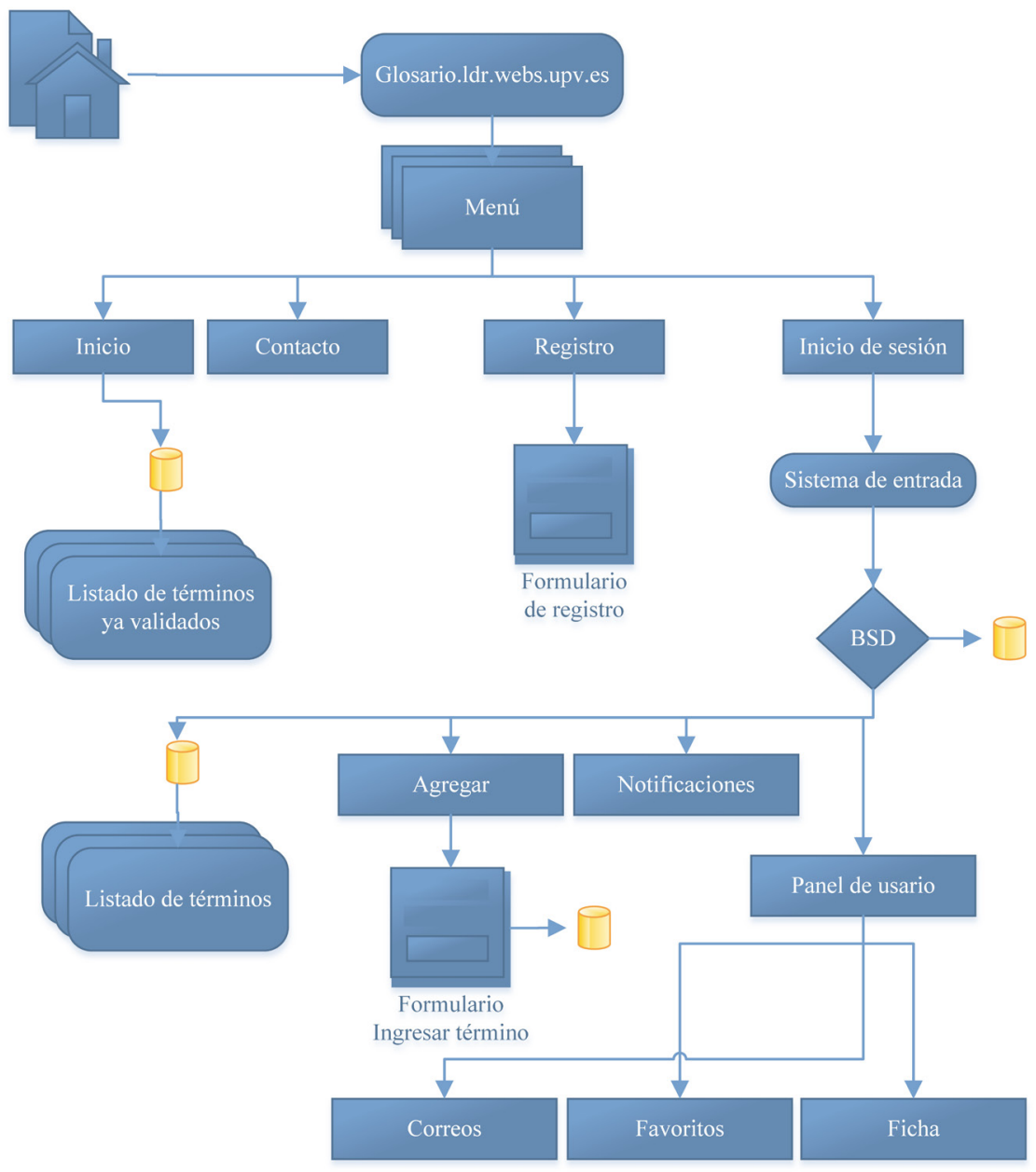

Fig. 1 Esquema del sitio web 'Glosario $C+R$ ' 


\subsection{Diseño de la estrategia}

Como hemos dicho, una de las premisas que se tuvo tanto para el diseño como para la ejecución del sitio Glosario $C+R$ fue su sencillez. Se pensó que llevar a cabo un registro muy complicado, o extensos, iban a ser una barrera para su uso por parte del alumno/a. Por eso, desde la primera de las páginas que presenta el sitio debe ser totalmente intuitiva. Esa primera página la forman el grupo de términos que ya han pasado un proceso de selección previo y de esta forma pueden ser consultados por el público en general (fig.2).

Los términos se muestran ordenados de forma alfabética y por entrada reciente. En esta página de inicio todos los que participan en el proyecto, tanto el estudiante como la administración, tienen un sistema de autentificación que les permite acceder a la gestión del sitio, desde donde se podrán ingresar términos o imágenes, valorar a través de votación las palabras inscritas o mantener correo interno entre los distintos integrantes del proyecto.

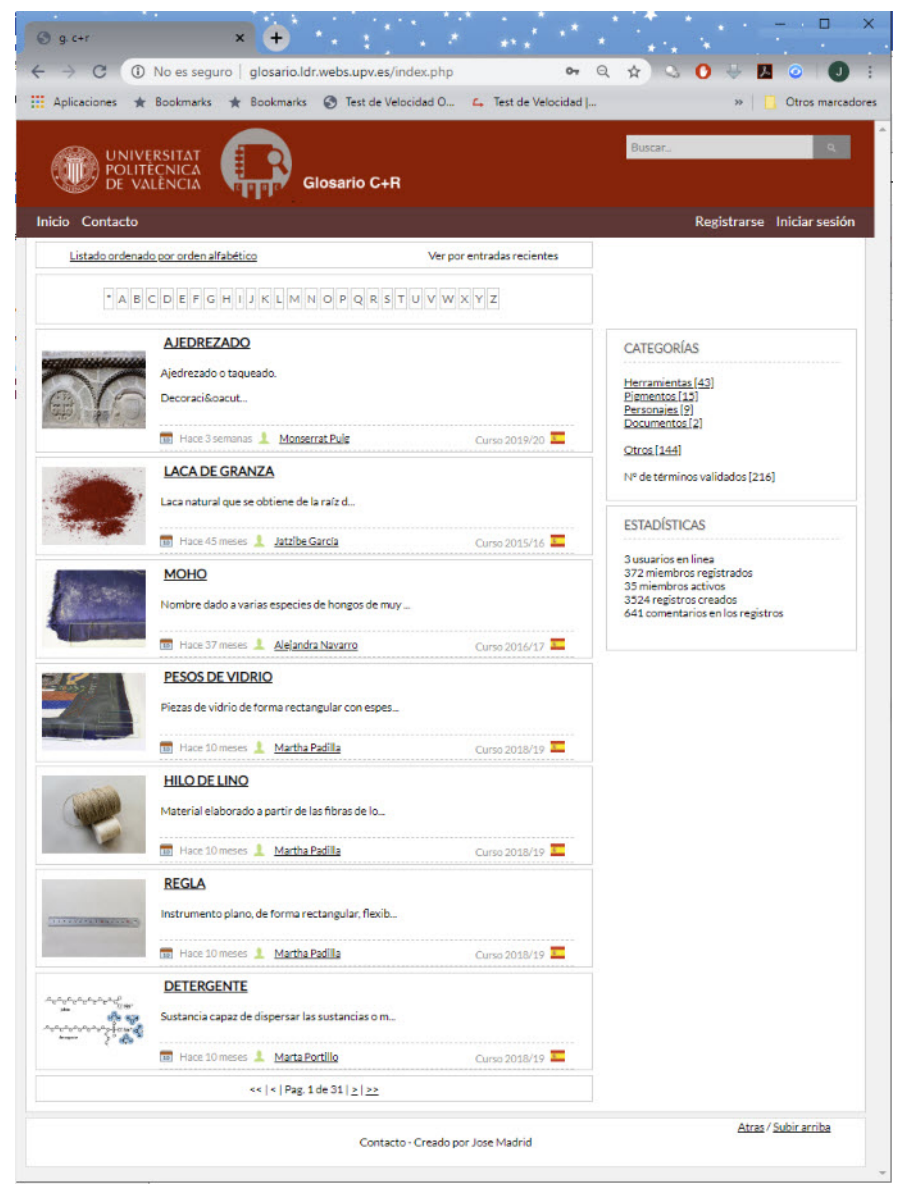

Fig. 2 Página de inicio del sitio web 'Glosario $C+R$ '

Tras su validación, el usuario registrado se encuentra con una segunda página donde, a modo de tablón, el administrador recoge sugerencias o normas de uso. A lo largo de estos 5 años, que lleva la aplicación activa, hemos comprobado que esta página tiene mucho interés para el sostenimiento del nivel de motivación y así mantener esta página viva. En ella los usuarios encuentran pistas y material para poder agregar nuevos términos.

Dentro de la barra de menú se encuentran varias opciones, como; redirigir al usuario a la página de 'inicio' donde están todos los términos presentes en la base de datos, una página de contacto con el 
administrador y la destinada a la posibilidad de 'agregar' un nuevo término. El sistema para agregar esos nuevos términos permite, además de ingresar el 'título', hacer una clasificación de este por su 'disciplina' y 'clase'. Tras la inserción de esta información, el usuario seguirá por varios pasos que le permitirán subir una imagen, o cabecera, para que acompañe al término en su etiqueta, o podrá añadir más imágenes que se colocaran a los pies de la descripción detallada del término que se ha subido presentadas como un carrusel.

En el lado derecho de la barra de menú existen más posibilidades de interacción con otros usuarios, como son un sistema de notificaciones personal, la recepción de correo interno entre usuarios o un ítem para marcar como 'favoritos' aquellos términos que se desee volver a revisar. También en esa parte de la barra de menú se tiene acceso a una página de perfil, donde se registra el curso al que pertenece o la bandera del país de procedencia y la posibilidad de cambiar su imagen de usuario. Todos estos detalles convierten al sitio en un espacio más amigable. Justo bajo de esta pequeña ficha se encuentra una estadística de su participación, con la información de; las palabras de las que es autor, los términos que tiene validados, las veces que ha votado por otros términos, las cabeceras que son propias y las que ha colocado, en otros términos, más las fotos que ha subido para ilustrar los términos no solo propios sino de otros usuarios.

En esta misma página el participante tiene la posibilidad de recoger en un archivo PDF con sus términos y ver el estado de estos, ya estén validados o no. En el acceso a un término hemos diferenciado dos posibilidades; por un lado, los propios que su autor podrá editar o borrar, hacer cambios en las fotos de cabecera o en las fotos del carrusel, mientras no estén validados y por otro lado los que son de otros usuarios a las que podrá votar en sentido positivo o negativo, pero siempre solo una vez. Además, podrá hacer cometarios a cualquiera de los términos que hay en la base de datos. Este tipo de opciones permite que el usuario se implique no solo subiendo términos nuevos, sino mejorando los que ya existen (fig.3).

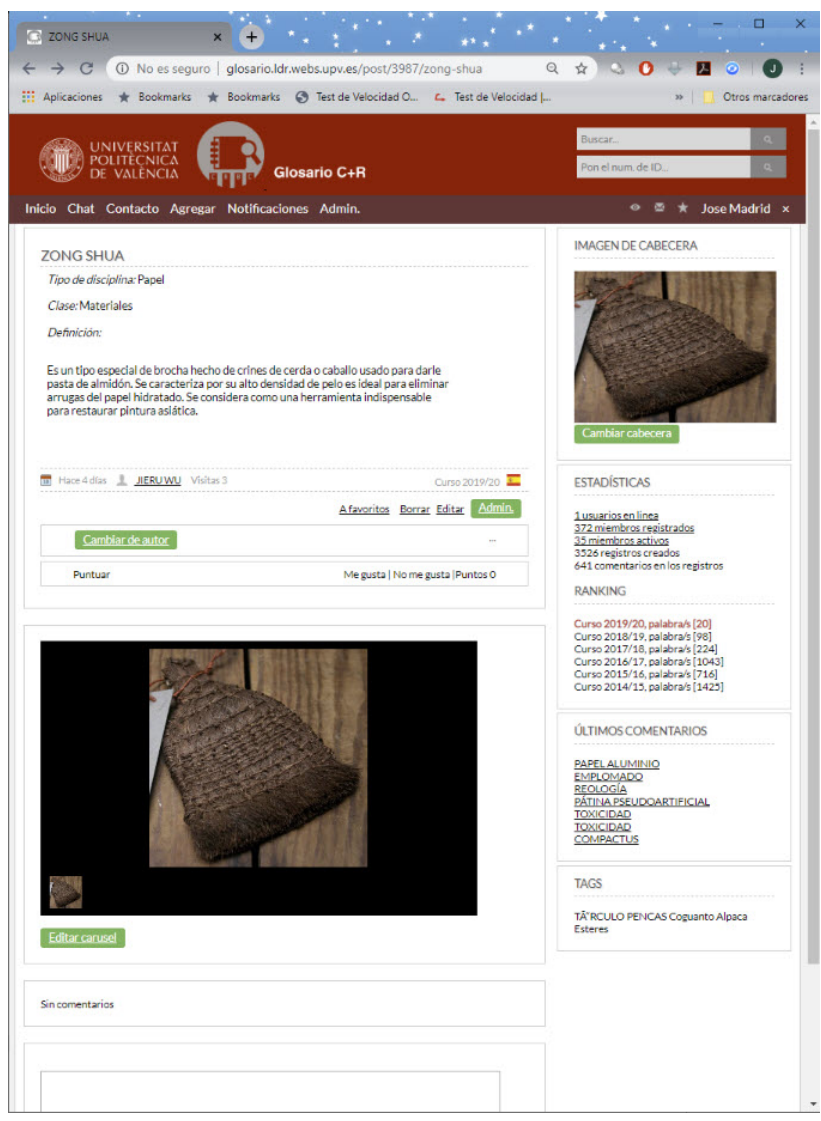

Fig. 3 Pantalla de términos 
En todo momento, el usuario tiene a la vista un panel situado al lado derecho de la página, donde se muestra la información a tiempo real de los usuarios que están en línea y con los que podrá establecer una conversación a través del 'chat' de la página, ver el ranking en el que se encuentra su curso con respecto a otros o el panel de los 'últimos comentarios' realizados.

Todas las fichas de los términos subidos mantienen la información de cuándo y quién los ha ingresado, dando la posibilidad de seguir a este usuario a su página de perfil y poder mandarle un correo o ver el listado de los términos que tiene. La información del término se completa con el número de visitas que el término ha recibido.

\subsection{Panel de administración}

Dentro de una labor sostenida en el tiempo, como es el caso, y que depende de que el alumno/a participe de forma voluntaria en ella, hemos visto que la labor de motivación se convierte en una parte muy importante para el mantenimiento de este recurso. Motivación que debe ser alimentada de forma constante por parte del administrador. Es por eso por lo que se han ido diseñando y mejorando las opciones que le permiten recoger información de forma automática a lo largo de estos años. Las opciones que tiene a su disposición el administrador se pueden dividir en dos, las acciones para consulta o mantenimiento y las acciones para contacto con el responsable del término, o los usuarios.

Las acciones de consulta y mantenimiento de la base de datos se ha demostrado que son indispensables. La duplicidad en los términos, problemas de visualización de las imágenes, son errores que se deben localizar rápidamente para el buen funcionamiento de sitio web. Para agilizar la labor del administrador en esta parte cuenta con distintas herramientas como;

- Panel de análisis; en este se recogen en una tabla el nombre de todos los participantes y el número de términos que ha ingresado. La información está ordenada, de mayor a menor, por los términos con la posibilidad de mandar un correo a cualquiera de ellos.

- Panel de análisis del curso actual; muy similar al panel anterior, pero recogemos la información de solo los alumnos/as del curso actual. Teniendo la información de los términos que han insertado, las cabeceras e imágenes incluidas, o los votos emitidos.

- Panel de revisión de cabeceras, fotos y localizador de fotos huérfanas; uno de los problemas de las aplicaciones que se basan en el empleo de una base de datos es el espacio que esta ocupa. El incluir imágenes de forma masiva en este tipo de sistemas se convierte, debido al peso de este tipo de archivos, en un problema. Este panel permite saber no solo el peso de los archivos o sus medidas, sino que le permite al administrador ponerse en contacto con el usuario para solicitarle un cambio puntual en la imagen que pueda presentar problemas. El localizador de las 'fotos huérfanas' permite localizar, para su posterior eliminación, de aquellos términos que han sido borrados.

- Palabras sin contenido y panel de localización de duplicados; en ambos paneles se pueden solucionar varios problemas, como la localización de las palabras que no han llegado a registrarse bien debido a un problema, o un fallo en el sistema, y que se quedan sin contenido. Por otro lado, las palabras que de forma reiterada se pueden ingresar en la aplicación. Esta reiteración provoca un duplicado del término y desde este panel el administrador puede ponerse en contacto con su responsable.

Y como para que la actividad se mantenga viva es importante crear cierto nivel de curiosidad en el alumno, Para ello el panel del administrador permite acciones de contacto con los usuarios, como: 
- Sistema de correo masivo; a través de este sistema el administrador puede mandar un correo a toda la comunidad que participa en este proyecto. Este sistema permite mandar un correo a todo el grupo activo, porque pertenece al curso actual, o a los que son de otros cursos y no están activos.

- Palabras más o menos votadas; esta información permite al administrador ir al término que más o menos votos ha recibido. En el caso de los términos más votados se podrá valorar si este puede ser validado y en el caso de los menos votados hacer la invitación para que se vuelvan a definir.

- Oferta de nuevas definiciones; una tarea que hemos automatizado son las denominadas 'palabras sugeridas'. A través de una consulta realizada a la base de datos podemos conocer aquellos términos cuya definición sea excesivamente corta. Desde esa misma página, el término se puede incluir en un panel y de forma automática los usuarios del curso actual reciben un correo con la invitación para volver a definirlo. Esta opción también se puede usar con los términos que tienen una votación negativa. Una vez enviado ese correo se actualiza el panel de 'notificaciones' recogiendo las palabras de las que se solicita una nueva definición.

\subsection{Sistema de valoración de la actividad de glosario}

Otro punto de interés dentro de la actividad fue la elaboración de un sistema de valoración, a modo de rúbrica, que fuera adecuado al grado de implicación del alumno/a con esta actividad (Mauricio et al., 2016; Blanco, 2008). Por un lado, se estableció un sistema de promedio ponderado tomando como referencia tanto el número de términos incluidos en la base de datos, como la inclusión de imágenes y el uso del sistema de valoración.

Por otro lado, también hemos elaborado una rúbrica para la valoración de los términos ingresados. En está rubrica (tabla 1) se valora de mayor a menor grado; la adecuación de su colaboración, el nivel de participación, el nivel de expresión de los términos ingresados, más la idoneidad de las imágenes subidas al recurso (fig.3). 
Tabla 1. Sistema de valoración de los términos ingresados

\begin{tabular}{|c|c|c|c|c|}
\hline Indicador & I1 (Malo) & I2 (Regular) & I3 (Bueno) & I4 (Excelente) \\
\hline $\begin{array}{c}\text { Participación y uso } \\
\text { del recurso }\end{array}$ & $\begin{array}{l}0(0 \%) \text { El estudiante } \\
\text { no ha participado en } \\
\text { ninguna de las } \\
\text { propuestas ofrecidas } \\
\text { en la actividad. }\end{array}$ & $\begin{array}{l}1(10 \%) \text { El } \\
\text { estudiante ha } \\
\text { participado en } \\
\text { alguna de las } \\
\text { propuestas ofrecidas } \\
\text { en la actividad, pero } \\
\text { no en todas. }\end{array}$ & $\begin{array}{l}1,5(15 \%) \mathrm{El} \\
\text { estudiante ha } \\
\text { participado en todas } \\
\text { las propuestas } \\
\text { ofrecidas en la } \\
\text { actividad, de una } \\
\text { manera efectiva. }\end{array}$ & $\begin{array}{l}3(30 \%) \text { El } \\
\text { estudiante ha } \\
\text { participado en todas } \\
\text { las propuestas } \\
\text { ofrecidas en la } \\
\text { actividad, de una } \\
\text { manera efectiva y } \\
\text { adoptando todos los } \\
\text { roles. }\end{array}$ \\
\hline Adecuación & $\begin{array}{l}0(0 \%) \text { El estudiante } \\
\text { no ha comprendido } \\
\text { las necesidades del } \\
\text { colaborador y sus } \\
\text { sugerencias no han } \\
\text { podido ser } \\
\text { consideradas en } \\
\text { ninguna de las } \\
\text { propuestas ofrecidas } \\
\text { en la actividad. }\end{array}$ & $\begin{array}{l}1(10 \%) \text { El } \\
\text { estudiante ha } \\
\text { comprendido las } \\
\text { necesidades del } \\
\text { colaborador y sus } \\
\text { sugerencias han } \\
\text { podido ser } \\
\text { consideradas en } \\
\text { alguna de las } \\
\text { propuestas ofrecidas } \\
\text { en la actividad. }\end{array}$ & $\begin{array}{l}2(20 \%) \text { El } \\
\text { estudiante ha } \\
\text { comprendido las } \\
\text { necesidades del } \\
\text { colaborador, } \\
\text { aportando ideas y } \\
\text { planteamientos } \\
\text { originales. Sus } \\
\text { sugerencias se han } \\
\text { considerado para la } \\
\text { mejora de la } \\
\text { propuesta. }\end{array}$ & $\begin{array}{l}3(30 \%) \text { El } \\
\text { estudiante ha } \\
\text { comprendido las } \\
\text { necesidades del } \\
\text { colaborador, } \\
\text { aportando ideas y } \\
\text { planteamientos } \\
\text { originales. Sus } \\
\text { sugerencias se han } \\
\text { tomado en cuenta } \\
\text { para la mejora de la } \\
\text { propuesta. }\end{array}$ \\
\hline $\begin{array}{l}\text { Sobre los términos; } \\
\text { nivel de expresión }\end{array}$ & $\begin{array}{l}0(0 \%) \text { El estudiante } \\
\text { no ha empleado de } \\
\text { forma adecuada la } \\
\text { gramática y el } \\
\text { vocabulario no se } \\
\text { ajusta a las } \\
\text { necesidades del } \\
\text { colaborador. }\end{array}$ & $\begin{array}{l}1(10 \%) \text { El } \\
\text { estudiante ha } \\
\text { empleado } \\
\text { adecuadamente la } \\
\text { gramática y el } \\
\text { vocabulario, aunque } \\
\text { ha necesitado de } \\
\text { corrección por parte } \\
\text { del administrador. }\end{array}$ & $\begin{array}{l}1,5(15 \%) \text { El } \\
\text { estudiante ha } \\
\text { empleado de manera } \\
\text { adecuada tanto la } \\
\text { gramática como el } \\
\text { vocabulario en todo } \\
\text { momento. }\end{array}$ & $\begin{array}{l}2(20 \%) \text { el } \\
\text { estudiante ha } \\
\text { empleado de manera } \\
\text { adecuada tanto la } \\
\text { gramática como el } \\
\text { vocabulario en todo } \\
\text { momento, y ha } \\
\text { participado en la } \\
\text { clasificación } \\
\text { taxonómica de los } \\
\text { términos. }\end{array}$ \\
\hline $\begin{array}{l}\text { Sobre las imágenes; } \\
\text { nivel de ideoneidad }\end{array}$ & $\begin{array}{l}0(0 \%) \text { El estudiante } \\
\text { no ha colaborado en } \\
\text { la implementación } \\
\text { de imágenes en la } \\
\text { propuesta. }\end{array}$ & $\begin{array}{l}0,5(5 \%) \text { El } \\
\text { estudiante ha } \\
\text { implementado } \\
\text { algunas imágenes en } \\
\text { la propuesta (entre } 1 \\
\text { y } 20 \text { imágenes), } \\
\text { aunque ha } \\
\text { necesitado de } \\
\text { corrección por parte } \\
\text { del administrador. }\end{array}$ & $\begin{array}{l}1(10 \%) \text { El } \\
\text { estudiante ha } \\
\text { implementado } \\
\text { algunas imágenes en } \\
\text { la propuesta (entre } \\
10 \text { y } 30 \text { imágenes), } \\
\text { pero ha necesitado } \\
\text { de corrección por } \\
\text { parte del } \\
\text { administrador. }\end{array}$ & $\begin{array}{l}2(20 \%) \text { El } \\
\text { estudiante ha } \\
\text { implementado } \\
\text { algunas imágenes en } \\
\text { la propuesta. El } \\
\text { número de imágenes } \\
\text { ha sido más de } 20 \text { y } \\
\text { en muy pocos casos } \\
\text { se ha corregido la } \\
\text { imagen. }\end{array}$ \\
\hline
\end{tabular}




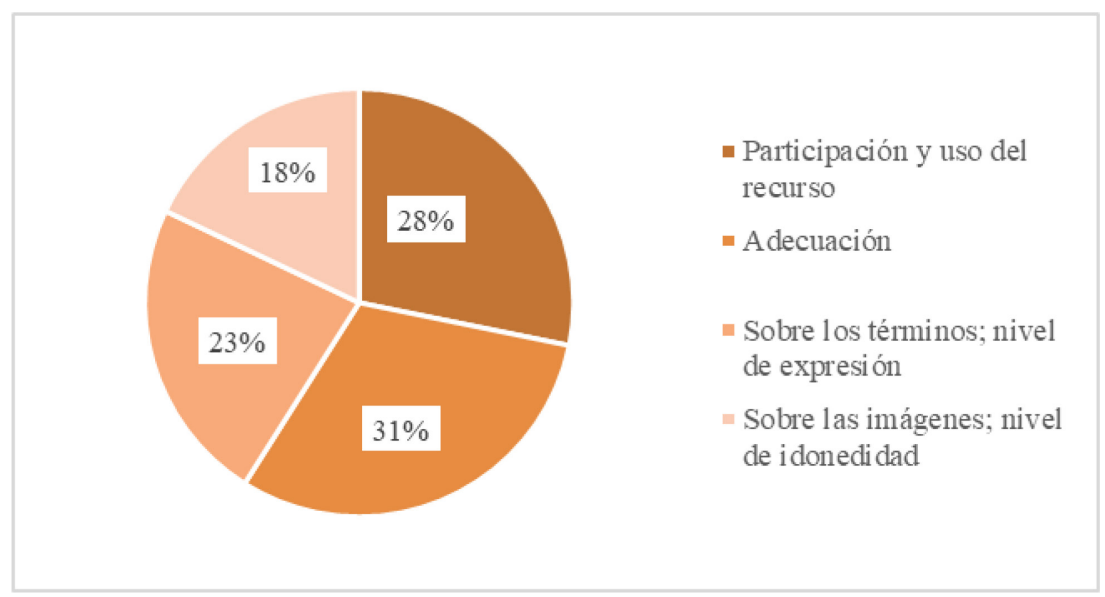

Fig. 3 Relación porcentual de los indicadores de evaluación

\section{Resultados}

La aplicación empezó a funcionar en el curso 2014/15 y en la fecha de entrega de este trabajo ya tiene registrados 3500 términos (tabla 2), con más de 32000 visitas. En números de todos estos términos, el $18,37 \%$ cuenta con foto denominada de cabecera y ya se han incorporado 650 imágenes para ilustrar los términos. Por otro lado, se han realizado más de 600 comentarios y se han efectuado 3047 votos, que han servido para la valoración y mejora de los términos ingresados. Todo ello ha llevado a la validación de más de 200 términos, que se pueden dar como completados.

Tabla 2. Estadista de uso; número de términos y número decabeceras más su porcentaje

\begin{tabular}{|c|c|c|c|}
\hline Curso & $\mathbf{N}^{\mathbf{0}}$ de términos & $\mathbf{\%}$ & $\mathbf{N}^{\mathbf{0}}$ fotos de cabecera (\%) \\
\hline $2014 / 2015$ & 1425 & 41 & $172(12 \%)$ \\
\hline $2015 / 2016$ & 716 & 20 & $223(21 \%)$ \\
\hline $2016 / 2017$ & 1043 & 30 & $81(36 \%)$ \\
\hline $2017 / 2018$ & 224 & 6 & $64(65 \%)$ \\
\hline $2018 / 2019$ & 98 & 3 & $644(18 \%)$ \\
\hline Totales & 3522 & & \\
\hline
\end{tabular}

La labor la ha realizado un conjunto de 370 miembros, que siguen registrados a lo largo de 5 años. En detalle, a lo largo de estos años y teniendo en cuenta que la colaboración es totalmente voluntaria, ha participado el 83,29\% de los alumnos/as matriculados en esta asignatura desde el curso 2014/15 (tabla 3).

En esta misma tabla se recoge en porcentaje los términos incluidos. Se ve una caída muy drástica en los dos últimos años debido fundamentalmente a la gran cantidad de términos ya ingresados en la base de datos. En estos dos últimos años se ha visto compensada la participación del alumnado mejorando las definiciones ya incluidas, la inclusión de imágenes para ilustrar los términos tanto en la cabecera (fig.4) como en llamado carrusel y sobretodo en el uso del sistema de votación. 
Tabla 3. Número de paricipantes y porcentajes

\begin{tabular}{|c|c|c|c|}
\hline Curso & $\begin{array}{c}\mathbf{N}^{\mathbf{o}} \text { de alumnos/as } \\
\text { matriculados }\end{array}$ & $\begin{array}{c}\mathbf{N}^{\mathbf{a}} \text { de alumos } \\
\text { participantes (\%) }\end{array}$ & $\begin{array}{c}\text { Palabras por año } \\
(\%)\end{array}$ \\
\hline $2014 / 2015$ & 83 & $80\left(96^{\prime} 39 \%\right)$ & $40^{\prime} 46$ \\
\hline $2015 / 2016$ & 86 & $73\left(84^{\prime}, 88 \%\right)$ & $20^{\prime} 33$ \\
\hline $2016 / 2017$ & 85 & $80\left(94^{\prime} 12 \%\right)$ & $29^{\prime} 61$ \\
\hline $2017 / 2018$ & 68 & $44\left(64^{\prime} 71 \%\right)$ & $6^{\prime} 36$ \\
\hline $2018 / 2019$ & 85 & $62\left(72^{\prime} 94 \%\right)$ & $2{ }^{\prime} 78$ \\
\hline Totales & 407 & $339\left(83^{\prime} 29 \%\right)$ & \\
\hline
\end{tabular}

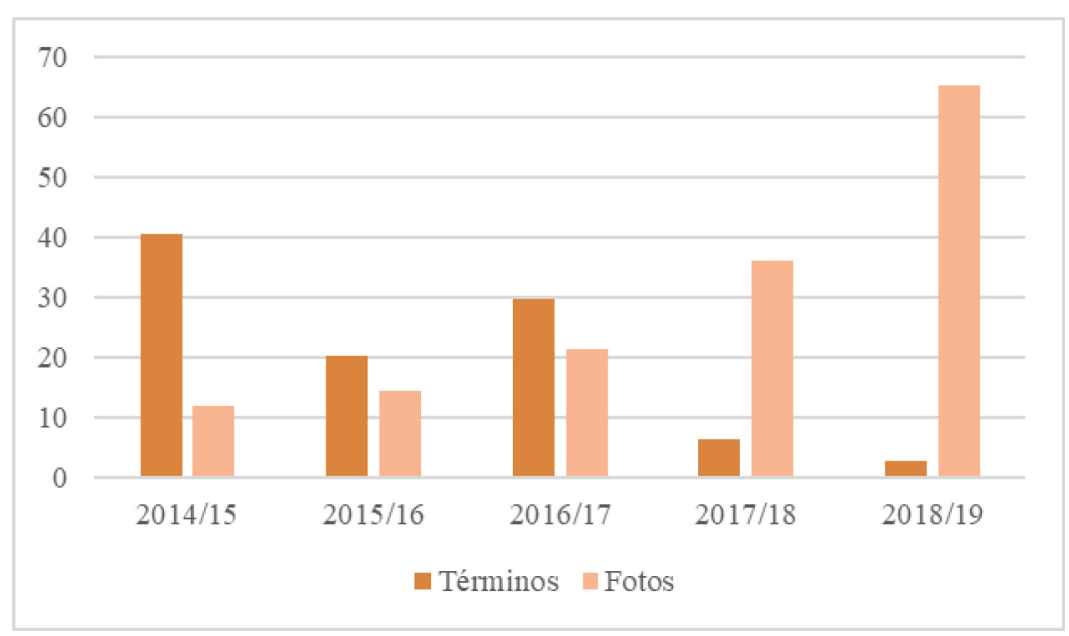

Fig. 4 Relación de inclusión de términos e imágenes

En detalle, las 32000 visitas se pueden agrupar en varios rangos que reflejan el siguiente valor en porcentaje; términos que han recibido menos de 5 vistas forman el $80,62 \%$, los términos que han recibido entre 5 y 20 visitas se llevan el 13,47\%, el rango de vistas entre los valores de 20 a 40 visitas son el $1,64 \%$ y el conjunto de computo de visitas entre las 40 y las 100 se lleva el 4,26\%. Destacando que hay un $1 \%$ (35 términos) que han recibido más de 100 vistas (fig.5).

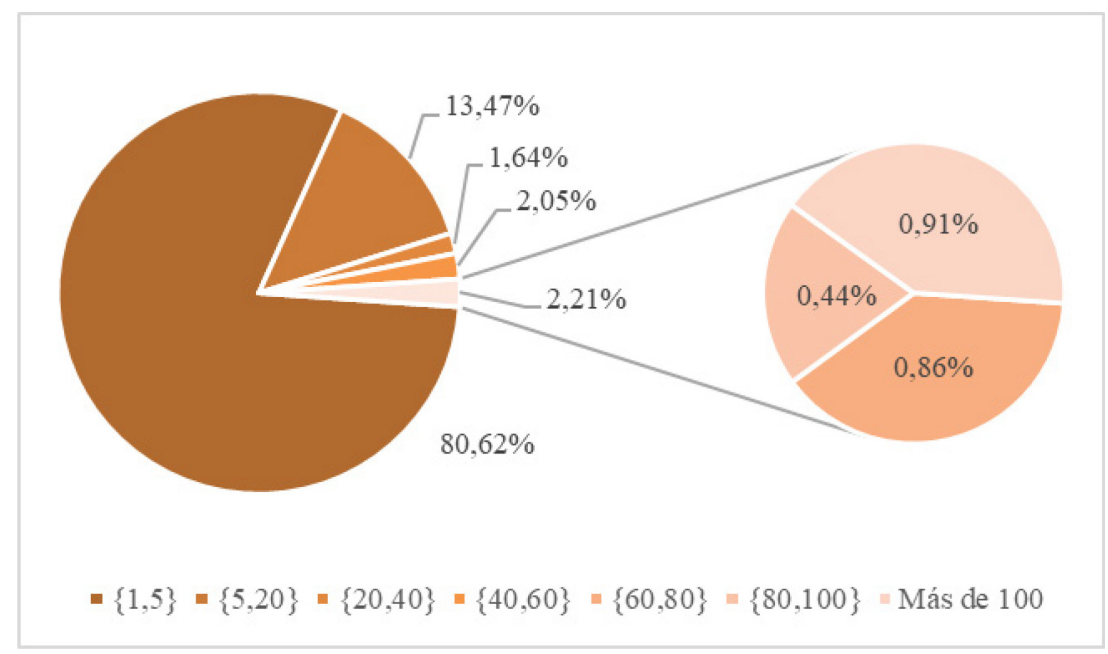

Fig. 5 Relación de visitas 
A lo largo de estos años hemos podido constar que existe una relación, casi directa, entre los alumnos/as que mejores calificaciones han obtenido en la asignatura y que más han participado en todas las posibilidades que ofrece este sitio Web, como es; el agregar palabras, subir fotos, hacer comentarios y usar el sistema de voto para la valoración de las palabras que aparecen en la base de datos. Siendo los mismos usuarios los que nos han ido ayudando a mejorar este sitio web; como ha sido la posibilidad de exportar sus palabras a un archivo tipo PDF, la inclusión de ese panel de estadísticas propio de cada usuario, o la mejora del sistema de clasificación de los términos.

De la colaboración también surgió el sistema de clasificación de las palabras en categorías. Este sistema les permite hacer un segundo nivel de filtrado de los términos, lo que les ayuda a hacer una revisión más abierta de todos los términos, pero desde las áreas de interés que ellos mismos sugirieron.

\section{Conclusiones}

Este trabajo podría ser una prueba más de que la implementación de recursos tecnológicos de apoyo al aprendizaje mejora la calidad de la enseñanza universitaria, no solo de tipo formativo sino a nivel de relación (Núñez, 2012; Del Moral, 2012; García- Ruiz, 2014). En este caso, el sitio web Glosario $C+R$ está pensado como una plataforma de documentación, donde se recoge la búsqueda colectiva de referencias de interés por parte del alumno, que gracias a su participación ha demostrado ser un repositorio de gran interés.

Uno de los datos que apoya esta afirmación es la alta participación del alumno/a que con un valor del $83 \%$ de la totalidad, de forma voluntaria, ha ayudado a su sostenibilidad desde el curso académico 2014/15 hasta la actualidad. Participación que, a lo largo de estos 5 años, igualmente se ve reflejada en las 32000 visitas realizadas a los 3500 términos recogidos en la base de datos, apoyados con 650 imágenes para ilustrarlos, 600 comentarios para mejorarlos y se han efectuado 3047 votos.

Esta colaboración ha ayudado, de una forma activa, a la mejora de la aplicación. Recogiendo las sugerencias de los alumnos/as que han modificado las herramientas y sumado nuevas posibilidades. Todo este trabajo ha permitido recurrir a sus datos en cualquier momento y utilizarse como argumento visual para explicar determinadas cuestiones, tanto por parte del alumnado como del profesor.

Y como apunta Díaz (1999), si en el pasado se hablaba de la creatividad del profesor hoy debemos hablar de binomio alumno/a-profesor como generador de esa creatividad. Formando así un aprendizaje significativo que implica un proceso constructivo activo y continuo del conocimiento. Proceso de aprendizaje que se ve reforzado con este tipo de estrategias.

\section{Referencias}

AGUADED, J.I. (2001). “Aprender y enseñar con las tecnologías de la comunicación” en Agora Digital, 1, p.1-13. $<$ http:// www.uhu.es/agora/digital/numeros/numeros_ppal.htm> [Consulta: 17 de marzo de 2020]

ASTIN, A (1993). What matters in College? Four Critical Years Revisited. San Francisco, CA: Josey-Bass.

BLANCO, A. (2008). Las rúbricas: un instrumento útil para la evaluación de competencias en la enseñanza universitaria centrada en el aprendizaje, OCTAEDRO, ICE-UB, Barcelona.

CARPENTER, J. (2014). "Twitter's capacity to support collaborative learning” en International Journal of Social Media and Interactive Learning Environments, 2(2), pp. 103-118. 
CARPENTER, J.P., y KRUTKA, D.G. (2014). "How and why educators use Twitter: A survey of the field" en Journal of Research on Technology in Education 46(4), pp. 414-434.

CHUNG, J. (1991). "Collaborative learning strategies: The design of instructional environments for the emerging new school” en Educational Technology, vol. 32(12), pp. 15-22.

CLEMANS, A. (2015). "Lifelong Learning in Practice” en J. Yang, C. Schneller, \& S. Roche (Eds.). The Role of Higher Education in Promoting Lifelong Learning. (pp. 147-154). Germany: UNESCO Institute for Lifelong Learning. <http://unesdoc.unesco.org/images/0023/002335/233592e.pdf> [Consulta: 3 de marzo de 2020]

DE MIGUEL, M., ALFARO, I., APODACA, P., ARIAS, J. M., GARCIA, E., LOBATO, C. Y PÉREZ, A. (2005). Modalidades de enseñanza centradas en el desarrollo de competencias. Orientaciones para promover el cambio metodológico en el Espacio Europeo de Educación Superior. Madrid: Programa de Estudios y Análisis. Dirección General de Universidades. Ministerio de Educación y Ciencia.

DEL MORAL, E.; VILLALUSTRE, L. (2012). "University teaching in the 2.0 era: virtual campus teaching competencies" en Revista de Universidad y Sociedad del Conocimiento (RUSC). vol. 9, No 1. pp. 231-244

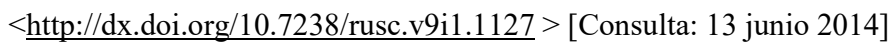

DÍAZ, F. (1999). Estrategias docentes para un aprendizaje significativo. México: MacGraw-Hill. Interamericanas.

DÍAZ-BARRIGA, F. (2002). Estrategias docentes para un aprendizaje significativo. México: McGraw-Hill.

DILLENBOURG, PP. (1999). "What do you mean by collaborative learning?" en PP. Dillenbourg (Ed.). Collaborative-learning: Cognitive and Computational Approaches (pp. 1-19). Oxford: Elsevier. $<$ https://telearn.archives-ouvertes.fr/hal-00190240> [Consulta: 17 de marzo de 2020]

DUNLAP, J.C., y LOWENTHAL, P.R. (2009). “Tweeting the night away: Using Twitter to enhance social presence" en Journal of Information Systems Education, 20(2), pp. 129-135. < https://aisel.aisnet.org/jise/vol20/iss2/2/> [Consulta: 17 de marzo de 2020]

GARCÍA, D. y AMANTE, B. (2006). “Algunas experiencias de aplicación del aprendizaje colaborativo y del aprendizaje basado en proyectos" en I Jornadas de Innovación Educativa. Zamora: Escuela Politécnica Superior de Zamora. <http://upcommons.upc.edu/e-prints/handle/2117/9489> [Consulta: 17 de marzo de 2020].

GARCÍA-RUIZ, R., GONZÁLEZ, N. \& CONTRERAS, PP. (2014). "Competency training in universities via projects and Web 2.0 tools. Analysis of an experience" en Revista de Universidad y Sociedad del Conocimiento (RUSC). vol. 11, No 1. pp. 61-75. <http://dx.doi.org/10.7238/rusc.v11i1.1713 > [Consulta: 5 de marzo de 2020]

GARRIGOS-SIMON, F.J., OLTRA, J.V., MONTESA-ANDRÉS, J.O., NARAGAJAVANA, Y., y ESTELLESMIGUEL, S. (2015). "The use of Facebook and Social Networks to Imporve Education" en Dirección y Organización, 55, pp. 4-10.

GERRITSEN, R. (1999). "Do students study more throughly within a problem-based learning environments course" en J. Hommes (Ed) Educational innovation in Economics y Business IV: Learning in a changing environment (pp. 127-141). Dordrecth / Boston / London: Kluwer Academic Publishers.

GROSSECK, G., y HOLOTESCU, C. (2008). "Can we use twitter for educational activities?” en 4th International Scientific Conference eLSE "eLearning and Software for Education”, Bucharest, April 17-18, 2008. Accessed 15 October, 2015. $<$ http://citeseerx.ist.psu.edu/viewdoc/summary?doi=10.1.1.382.9553 > [Consulta: 5 de marzo de 2020]

GUZMÁN, A.P., DEL MORAL, M.E., y GONZÁLEZ, F. (2012). "Usos de Twitter en las universidades iberoamericanas" en Revista Latinoamericana de Tecnología Educativa, 11(1), 27-39. $<$ https://riunet.upv.es/bitstream/handle/10251/58494/Gonz\%C3\%A1lez-Ladr\%C3\%B3n-de-Guevara\%2C\%20F\%20$\%$ 20Uso $\% 20 \mathrm{de} \% 20$ Twitter $\% 20 \mathrm{en} \% 20$ las $\% 20$ universidades $\% 20$ iberoamericanas.pdf?sequence $=2>$ [Consulta: $17 \mathrm{de}$ marzo de 2020]

HAKE, R. (1998). "Interactive Engagement versus Traditional Methods: A six-Thousand-Student Survey of Mechanics Test data for Introductory Physics Courses", en American Journal of Physics, vol. 66, №. 1, pp. 64-74. <http://www.montana.edu/msse/Data analysis/Hake 1998 Normalized gain.pdf $>$ [Consulta: 17 de marzo de 2020] 
JOHNSON, D.W., JOHNSON, R.T., y HOLUBEC, E.J. (1998). Advanced cooperative learning (2 ${ }^{a}$ ed). Edina, MN: Interaction Book Company.

KAGAN, S. (1989). "The structural approach to cooperative learning” en Educational leadership, 47(4), pp. 12-15.

LAAL, M., y LAAL, M. (2012). “Collaborative learning: what is it?” en Journal of Procedia-Social and Behavioral Sciences, 31, pp. 491-495.

MAURICIO, M., SERNA, E., VALLÉS, S., ALDASORO, M., y VILA, J. (2016). "Diseño de una rúbrica para evaluar trabajos en grupo: revisión y reflexión" en Congreso de Innovación Educativa y Docencia en Red, InRed 2016. Universitat Politècnica de València. <http://hdl.handle.net/10251/83415> [Consulta: 12 de marzo de 2020]

McCAFFERTY, S.G., JACOBS, G.M., y DASILVA, A.C. (2006). Cooperative Learning and Second Language Teaching. Cambridge: Cambridge University Press.

MIGUEL, V., y FERNÁNDEZ, M. (2013). "Redes Sociales y Construcción del Conocimiento" en A. B Martínez y N. Hernández (coord.) Teoría y Práctica de las Comunidades Virtuales de Aprendizaje. Caracas: Consejo de Desarrollo Científico y Humanístico de la Universidad Central de Venezuela (CDCH-UCV).

NOGUERA, I. (2015). "Modelos flexibles de formación: una respuesta a las necesidades actuales" en Revista del Congreso Internacional Docencia Universitaria e Innovación (CIDUI), 2, pp.3-14. $<$ https://www.cidui.org/revistacidui/index.php/cidui/article/download/630/606> [Consulta: 12 de marzo de 2020]

NUÑEZ E., y VACA JPP. (2012). "Creación y uso de una plataforma web como apoyo a las clases de aula" en RELADA - Revista electrónica de ADA-Madrid, 6(3), pp. $233-243$. $<$ http://polired.upm.es/index.php/relada/article/view/1915 > [Consulta: 12 de marzo de 2020]

POZO, J.I., y MONEREO, C. (1999). El aprendizaje estratégico: enseñar a aprender desde el currículo. Madrid: Santillana/Aula XXI.

ROMNEY, J.C. (1997). "Collaborative learning in a translation course" en Canadian Modern language Review, vol. 54 , pp. $48-67$.

SLAVIN, R. (1990). Cooperative learning: Theory, research and practice. Englewood Cliffs, NJ: Prentice Hall.

SMITH, B.L., y MACGREGOR, J.T. (1992). "What is Collaborative Learning?" en A. Goodsell, M. Mahler, V. Tinto, B. L. Smith y J. MacGregor (Eds). Collaborative Learning: A Sourcebook for Higher Education (pp. 9-22). Pennsylvania State University, USA: National Center on Postsecondary Teaching, Learning, and Assessment Publishing.

STEWART, R.A. (2007). "IT enhanced project information management in construction: Pathways to improved performance and strategic competitiveness" en Automation in Construction, 16(4), pp. 511-517.

SUÁREZ C., y GROS B. (2012). Aprender en red de la interacción a la colaboración. Barcelona: UOC.

SUAREZ, C., y GROS, B. (2013). Aprender en red. De la interacción a la colaboración. Barcelona: Universitat Oberta de Catalunya.

TESS, P.A. 2013. "The role of social media in higher education classes (real and virtual)-A literature review" en Computers in Human Behavior, 29(5), pp. A60-A68.

THOMS, B., y ERYILMAZ, E. (2015). "Introducing a twitter discussion board to support learning in online and blended learning environments" en Education and Information Technologies, 20 (2), pp. 265-283.

VANHOOF, J., y VAN PETEGEM, PP. (2005). "Feedback of performance indicators as a strategic instrument for school improvement" en REICE - Revista Electrónica Iberoamericana sobre Calidad, Eficacia y Cambio en Educación, vol. 3, № . 1. <http://www.redalyc.org/pdf/551/55130119.pdf > [Consulta: 17 de marzo de 2020]

WESTERLUND, L., y KAIVO-OJA, J. (2012). "Digital evolution - from information society to ubiquitous society" en Service Design: On the Evolution of Design Expertise, Lahti University of Applied Sciences Series A, Part III, pp. 137-153. < https://www.servicedesignmaster.com/wordpress/wp-content/uploads/2016/10/Service-Design-onthe-evolution-of-design-expertise.pdf\#page $=139>$ [Consulta: 12 de marzo de 2020] 